\title{
COVID-19 Infection and Homozygous SS Sickle Cell Disease in Children: About Two Cases in Ziguinchor/Senegal
}

\section{Lamine Thiam ${ }^{1}$, Noel Magloire Manga1, Chérif Mouhamadou Aidara ${ }^{1}$, Amadou Lamine Fall ${ }^{2}$, Ibrahima Diagne ${ }^{3}$, Ousmane Ndiaye ${ }^{2}$}

${ }^{1}$ Assane Seck University of Ziguinchor, Ziguinchor Peace Hospital, Ziguinchor, Senegal

${ }^{2}$ Cheikh Anta Diop University in Dakar, Albert Royer Children's Hospital in Dakar, Dakar, Senegal

${ }^{3}$ Gaston Berger University of Saint Louis, Saint Louis Regional Hospital, Saint Louis, Senegal

Email: ^thiamlkt@yahoo.fr

How to cite this paper: Thiam, L., Manga, N.M., Aidara, C.M., Fall, A.L., Diagne, I. and Ndiaye, O. (2020) COVID-19 Infection and Homozygous SS Sickle Cell Disease in Children: About Two Cases in Ziguinchor/Senegal. Open Journal of Pediatrics, 10, 744-750.

https://doi.org/10.4236/ojped.2020.104075

Received: November 8, 2020

Accepted: December 27, 2020

Published: December 30, 2020

Copyright $\odot 2020$ by author(s) and Scientific Research Publishing Inc. This work is licensed under the Creative Commons Attribution International License (CC BY 4.0).

http://creativecommons.org/licenses/by/4.0/

\begin{abstract}
The World Health Organization declared that corona virus diseases-19 (COVID-19) is a public health emergency. The COVID-19 pandemic is more likely to cause disaster in developing area including West Africa due to limited medical resources. COVID-19 reportedly causes severer conditions in adults with advanced age and in patients with underlying comorbidities including sickle cell anemia. We recently experienced two pediatric patients with sickle cell disease (SS), who had COVID-19. We here highlight the difficulties of management and the severity of COVID-19 infection in children with homozygous sickle cell SS.
\end{abstract}

\section{Keywords}

COVID 19 Infection, Sickle Cell Disease, Child

\section{Introduction}

Severe Acute Respiratory Syndrome Coronavirus 2, also known as COVID-19, has spread rapidly around the world since its outbreak in China. It constitutes a health emergency of international concern [1]. The infection may remain asymptomatic or manifest as cough, fever, anosmia, dyspnea, especially in the elderly [2]. In children, the clinical picture is far from being specific and may include, in addition to respiratory signs, digestive disorders. According to several authors, the infection is less serious in children compared to adults [3]. 
Although the clinical features of this disease are not yet fully understood, the severe form is thought to occur mainly in adults with advanced age and those with underlying comorbidities [4]. Sickle cell disease is an immune-depressing disorder that puts patients at a higher risk of respiratory infections and serious pulmonary complications such as acute chest syndrome [5]. Here we report two pediatric cases of COVID-19 who had SS sickle cell anemia and presented with severe symptoms; one had recovered and the other was deceased.

\section{Clinical Case 1}

An 18-month-old infant, male, weight $9 \mathrm{~kg}$, was seen at the Ziguinchor peace hospital for a cough, rhinorrhea and fever that had progressed for 7 days. The parents had consulted two days after the onset of the signs at a local pharmacy which had prescribed amoxicillin plus clavulanic acid, paracetamol. This symptomatology worsened with dyspnea requiring consultation in our department. The examination noted a temperature of $40^{\circ} \mathrm{C}$, severe hypoxic respiratory distress with $93 \% \mathrm{SaO}_{2}$ in ambient air; severe mucocutaneous pallor. The biological assessment returned with the blood count (White Blood Cells: $18,460 / \mathrm{mm}^{3}$; Hemoglobin: $6.0 \mathrm{~g} / \mathrm{dl}$; Platelets: 382,000/(mm³), the C-Reactive Protein: $24 \mathrm{mg} / \mathrm{l}$. The plasmodium falciparum rapid diagnostic test was negative. The blood culture was negative. A nasopharyngeal swab was positive for COVID-19. Emmel's test (TE) was positive and hemoglobin electrophoresis found sickle cell anemia with an SS profile (Hb S 75.6\%; Hb A2 2.0\% and Hb F 22.4\%). Chest x-ray: bilateral alveolar syndrome (Figure 1). Thoracic CT, done on the 10th day of hospitalization, showed the persistence of the alveolar syndrome (Figure 2). Severe pneumonia in a field of homozygous SS sickle cell disease was suggested. The same day, the child was admitted to the pediatric department of the Ziguinchor Peace Hospital due to lack of space at the Ziguinchor Epidemic Treatment Center (CTE). Bi-antibiotic therapy based on cefotaxime $500 \mathrm{mg} \times 3 / \mathrm{d}$, gentamycin

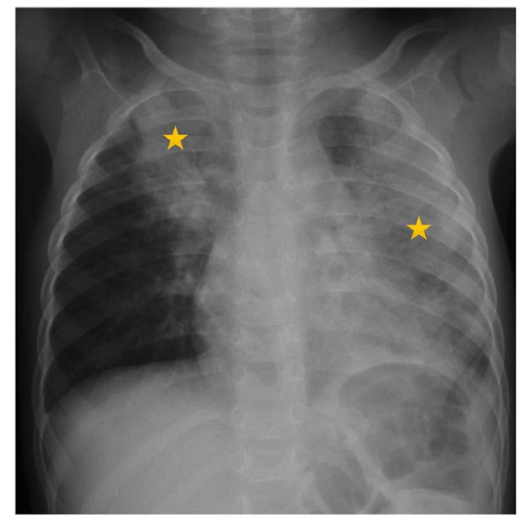

(a)

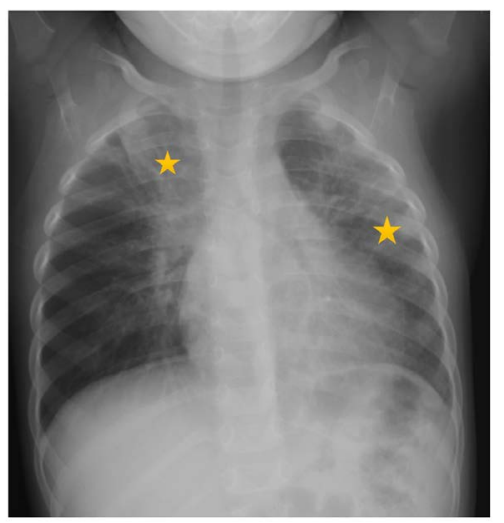

(b)

Figure 1. Frontal chest x-ray of an 18-month-old infant showing an alveolar syndrome involving the right upper lobe and the left lingula (stars in (a)). Monitoring after 10 days of treatment shows a clear lesion reduction with a frosted glass appearance associated with less alveolar filling in the same regions (stars in (b)). 


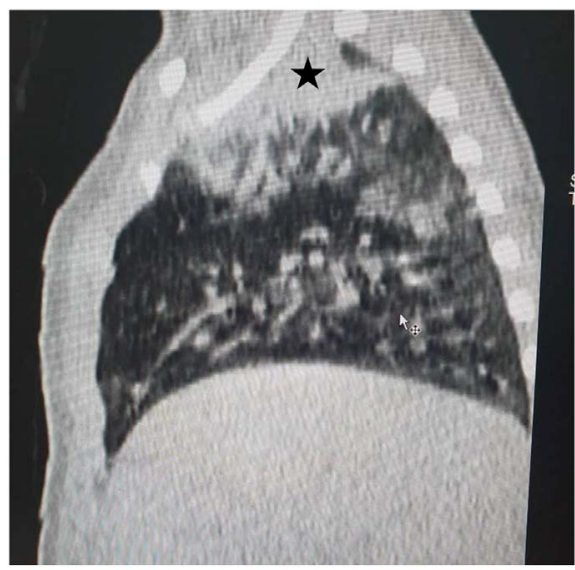

(a)

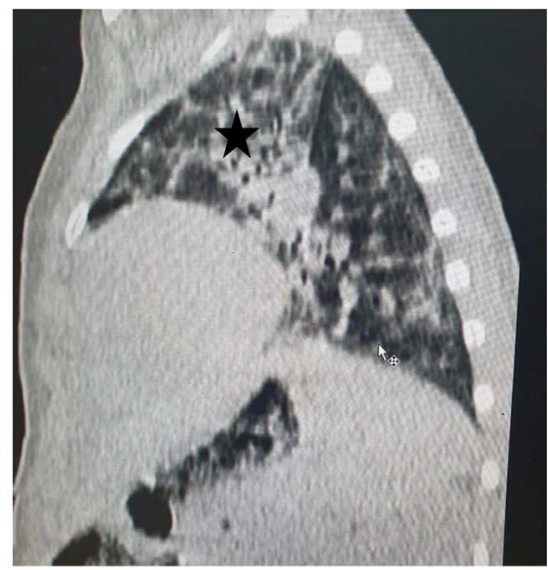

(b)

Figure 2. Chest CT of an 18-month-old infant, showing the persistence of the predominant alveolar syndrome on the right upper lobe (star in (a)) associated with a ground glass appearance on the left upper lobe (star in (b)).

$40 \mathrm{mg} / \mathrm{d}$ was started after collection of the blood culture. Antibiotic therapy was combined with an anti-pyretic based on perfalgan $13 \mathrm{ml}$ every 6 hours, folic acid 1 tablet every two days, hydration: $1000 \mathrm{ml}$ in 24 hours and oxygenation through glasses: 3 1/minutes. A blood transfusion of $90 \mathrm{ml}$ of red blood cell pellet was made over 4 hours at $22.5 \mathrm{ml} /$ hour.

In view of the COVID-19 positivity, additional treatment with azithromycin, zinc and vitamin $\mathrm{C}$ was added on the third day. The patient was discharged on the 10th day of hospitalization with stable apyrexia and complete improvement in clinical signs. Figure 3 shows the change in temperature and in oxygen saturation during hospitalization.

\section{Clinical Case 2}

15-year-old boy, weight $25 \mathrm{~kg}$, was received at the center 08/04/2020 at the health center of Thionck-Essyl for: dyspnea, cough and fever evolving for two days. The examination noted a temperature of $39^{\circ} \mathrm{C}$, severe respiratory distress; severe mucocutaneous pallor and being underweight. Oxygen saturation was not taken. Interrogation of his family members revealed a notion of sickle cell disease among the siblings. The biological assessment returned with the blood count

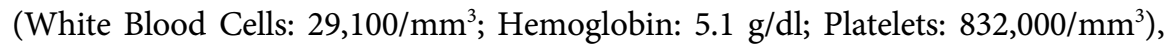
the C-Reactive Protein: $96 \mathrm{mg} / \mathrm{l}$. The plasmodium falciparum rapid diagnostic test was negative. A nasopharyngeal swab was positive for COVID-19. Emmel's test (TE) was positive and hemoglobin electrophoresis found sickle cell anemia with an SS profile ( $\mathrm{Hb} \mathrm{S} 78.6 \%$; $\mathrm{Hb} \mathrm{A} 2$ at $2.4 \%$ and $\mathrm{Hb} \mathrm{F}$ at $19.0 \%$ ). Blood culture and chest $\mathrm{x}$-ray were not performed.

Severe pneumonia on the ground of sickle cell disease has been mentioned. The parents refused to transfer the child to the Ziguinchor CTE. In front of this clinical picture, he was hospitalized at the Thionck-Essyl health center. Antibiotic-based treatment was started: ceftriaxone $1000 \mathrm{mg} /$ day, gentamicin $80 \mathrm{mg} /$ day, 


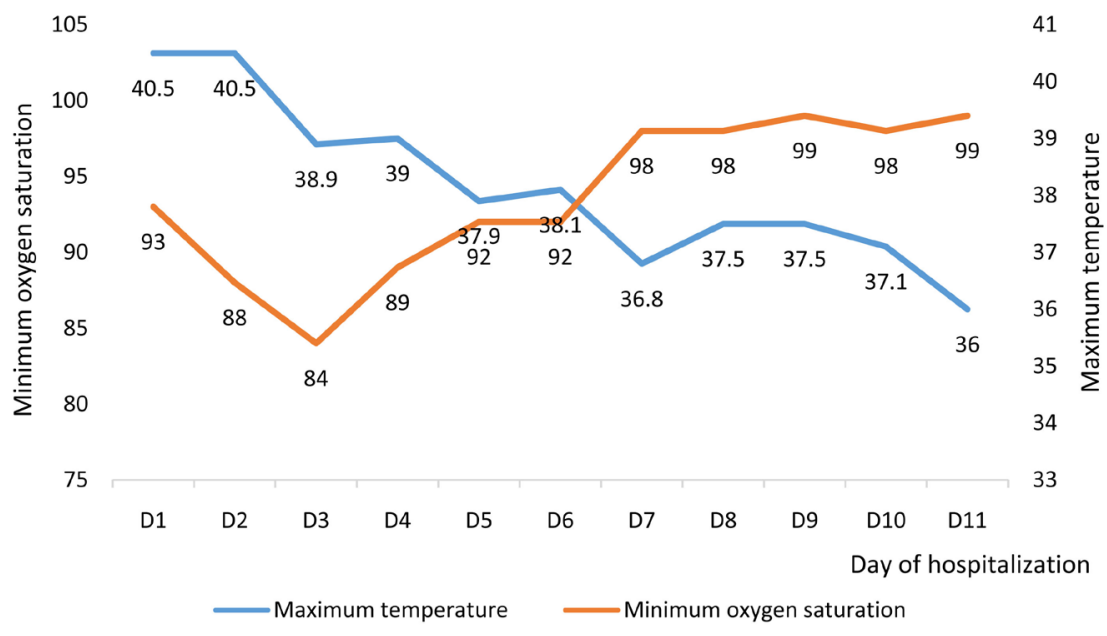

Figure 3. Evolution of the maximum temperature and minimum saturation in hospital for an 18-month-old infant.

azithromycin $250 \mathrm{mg} /$ day. Antibiotic therapy was associated with symptomatic treatment: paracetamol-based anti-pyretics $40 \mathrm{ml}$ every 6 hours, hydration: 500 $\mathrm{ml}$ of isotonic saline (SSI) in 24 hours, injectable iron, zinc and vitamin c. The patient died after 72 hours of hospitalization.

\section{Discussion}

Infectious complications are described as the leading cause of morbidity and mortality in children with sickle cell disease. The main factors explaining the high susceptibility of sickle cell patients to infections, including viral infections, are functional asplenia and phagocytosis disorders [6]. The most serious infections are bacteremia, meningitis, osteomyelitis, pneumonia. Pneumococcus and salmonella are the most common bacteria [7]. Mycoplasma pneumoniae and Chlamydia pneumoniae are often the cause of severe pneumonia leading to acute chest syndrome [8]. Among viral infections, parvovirus B19 gives acute erythroblastopenia which is generally well tolerated. Influenza can cause respiratory crises and complications justifying vaccine prevention [8].

The coronavirus disease (COVID-19) outbreak caused by the novel Severe Acute Respiratory Syndrome Coronavirus 2 (SARS-CoV-2), has led to a global health emergency. Compared to the general population, patients with sickle cell disease are expected to be more severely affected by COVID-19 due to their pre-existing chronic morbidities. The supposed severity of this COVID 19 infection in this field of sickle cell disease is the occurrence of acute chest syndrome (ATS) which was the case for our two patients. STA is defined by any new pulmonary image, of the alveolar infiltrate type including at least one segment excluding atelectasis, associated with one of the following symptoms: chest pain, fever or dyspnea, in a patient with major sickle cell syndrome (homozygous SS or double heterozygous SC, $S \beta$ thalassemia) [8] [9]. ATS is the second reason for hospitalization of children with sickle cell disease and pediatric mortality is around 2\% [8]. However, respiratory deterioration with the onset of acute respi- 
ratory distress syndrome (ARDS) becomes synonymous with a major worsening of the prognosis with mortality between $22 \%$ and $27 \%$ in the pediatric population [10]. This acute pulmonary attack is rarely isolated, it is triggered by a number of causes or factors [9]. An American study evaluated, in 30 centers and over 671 episodes, the possible etiologies of ATS in an essentially pediatric population [8]. The results show a probable high frequency of viral infections (6\%), infections with atypical bacteria (7\%) and fat embolism (9\%).

Our two clinical cases presented with COVID 19 pneumonia responsible for STA.

For all these reasons, recommendations to health professionals and sickle cell patients have been made since the start of the pandemic [11].

The frosted-glass CT scan, found in clinic number 1, is quite common at the onset of Covid 19 infection. This was found in the study by Heshui Shi et al., [12]; in the study by Abdelbassat Ketfi et al., [13].

However, there are very few clinical studies confirming the potential severity of COVID 19 infection in children with sickle cell disease. In France, the results of a preliminary study comparing sickle cell and non-sickle cell patients infected with covid 19 show that COVID-19 is not more serious in patients with sickle cell disease SS and $S \beta$ and aged less than 45 years. The results of this study also suggest that vaso-occlusive crisis may complicate COVID-19 infection, occurring in approximately half of hospitalized patients with sickle cell disease [14]. The authors of this French study hypothesized a protective effect against COVID-19 in SS homozygous patients and $\mathrm{S} \beta$ composite heterozygotes. Indeed, the high plasma interferon concentration could fight against the viral replication of the SARS-CoV-2 coronavirus [15].

Once ATS has been diagnosed, management should be based on oxygenation; broad-spectrum antibiotic therapy (3rd generation cephalosporin, macrolide), ventilation as needed. Transfusion or transfusion exchange is often necessary [8]. Hydroxy urea is indicated after an ATS episode or when transfusion exchange is not available [16]. Our clinical case number 1 could be transfused. A week after discharge from the hospital, the child is put on hydroxy urea (hydrea *). This was not the case for clinical case number 2 .

The diagnosis of sickle cell anemia was made at the time of this pulmonary infection for both patients, which is in line with a late diagnosis of sickle cell anemia in our work context. Indeed, the diagnosis of sickle cell disease is rarely made before the age of two and neonatal screening is not systematic in Senegal [7]. Thus the early discovery of sickle cell anemia depends on the early warning signs. However, reliable neonatal screening techniques have been available for over 40 years and the systematization of neonatal screening in the Ziguinchor region would make it possible to detect early the majority of hemoglobinopathies, especially sickle cell anemia.

\section{Conclusion}

COVID-19 infection is severe in children with homozygous sickle cell SS. 
Transfusion is necessary to improve emergency care. We advise children and parents of children with sickle cell disease to comply with the specific recommendations of the national disease control directorate.

\section{Conflicts of Interest}

The authors declare that they have no links of interest.

\section{References}

[1] https://coronavirus.jhu.edu/map.html

[2] Buitrago-Garcia, D., Egli-Gany, D., Counotte, M.J., Hossmann, S., Imeri, H., Ipekci, A.M., et al. (2020) Occurrence and Transmission Potential of Asymptomatic and Presymptomatic SARS-CoV-2 Infections: A Living Systematic Review and Metaanalysis. PLOS Medicine, 17, e1003346. https://doi.org/10.1371/journal.pmed.1003346

[3] Zheng, F., Liao, C., Fan, Q.H., Chen, H.B., Zhao, X.G., Xie, Z.G., et al. (2020) Clinical Characteristics of Children with Coronavirus Disease 2019 in Hubei, China. Current Medical Science, 40, 275-280. https://doi.org/10.1007/s11596-020-2172-6

[4] Chow, N., Fleming-Dutra, K., Gierke, R., Hall, A., Hughes, M., Pilishvili, T., et al. (2020) Preliminary Estimates of the Prevalence of Selected Underlying Health Conditions among Patients with Coronavirus Disease 2019: United States, February 12-March 28, 2020. Morbidity and Mortality Weekly Report, 69, 382-386. https://doi.org/10.15585/mmwr.mm6913e2

[5] Steinberg, M.H. (1999) Management of Sickle Cell Disease. The New England Journal of Medicine, 340, 1021-1030. https://doi.org/10.1056/NEJM199904013401307

[6] Begue, P. and Castello-Herbreteau, B. (2001) Severe Infections in Children with Sickle Cell Disease: Clinical Aspects and Prevention. Archives de Pédiatrie, 8, 732-741. https://doi.org/10.1016/S0929-693X(01)80189-5

[7] Thiam, L., Boiro, D., Ndongo, A.A., Niang, B., Seck, N., Demly, I., et al. (2018) Acute Complications of Major Sickle Cell Syndromes at Ziguinchor Peace Hospital (HPZ), Senegal. Medecine Therapeutique Pediatrique, 21, 233-237.

[8] Vichinsky, E.P., Neumayr, L.D., Earles, A.N., Williams, R., Lennette, E.T., Dean, D., et al. (2000) Causes and Outcomes of the Acute Chest Syndrome in Sickle Cell Disease. National Acute Chest Syndrome Study Group. The New England Journal of Medicine, 342, 1855-1865. https://doi.org/10.1056/NEJM200006223422502

[9] Caboot, J.B. and Allen, J.L. (2008) Pulmonary Complications of Sickle Cell Disease in Children. Current Opinion in Pediatrics, 20, 279-287.

https://doi.org/10.1097/MOP.0b013e3282ff62c4

[10] Flori, H.R., Glidden, D.V., Rutherford, G.W. and Matthay, M.A. (2005) Pediatric Acute Lung Injury: Prospective Evaluation of Risk Factors Associated with Mortality. American Journal of Respiratory and Critical Care Medicine, 171, 995-1001. https://doi.org/10.1164/rccm.200404-544OC

[11] Taher, A.T., Bou-Fakhredin, R., Kreidieh, F., Motta, I., De Franceschi, L. and Cappellini, M.D. (2020) Care of Patients with Hemoglobin Disorders during the COVID-19 Pandemic: An Overview of Recommendations. American Journal of Hematology, 95, 208-210. https://doi.org/10.1002/ajh.25857

[12] Shi, H.S., Han, X.Y., Jiang, N.C., Cao, Y.K., Alwalid, O., Gu, J., et al. (2020) Radiological Findings from 81 Patients with COVID-19 Pneumonia in Wuhan, China: A 
Descriptive Study. The Lancet Infectious Diseases, 20, 425-434.

https://doi.org/10.1016/S1473-3099(20)30086-4

[13] Ketfi, A., Chabati, O., Chemali, S., Mahjoub, M., Gharnaout, M., Touahri, R., et al. (2020) Preliminary Data on the Clinical, Biological and Radiological Characteristics of Algerian Patients Hospitalized for Covid-19. Pan Africa Medical Journal, 35, 1-10. https://doi.org/10.11604/pamj.supp.2020.35.2.23807

[14] Arlet, J.-B., de Luna, G., Khimoud, D., et al. (2020) Prognosis of Patients with Sickle Cell Disease and COVID-19: A French Experience. The Lancet Haematology, 7, 632-634. https://doi.org/10.1016/S2352-3026(20)30204-0

[15] Chu, H., Wang, Y., Chai, Y., Hou, Y., et al. (2020) Comparative Replication and Immune Activation Profiles of SARS-CoV-2 and SARS-CoV in Human Lungs: An Ex Vivo Study with Implications for the Pathogenesis of COVID-19. Clinical Infectious Diseases, 71, 1400-1402. https://doi.org/10.1093/cid/ciaa410

[16] Odièvre, M.H. and Quinet, B. (2020) Drépanocytose chez l'enfant, EMC-Pédiatre. [4-080-A-20]. 